\title{
Una voz femenina en la poética de la tragedia neoclásica: Margarita Hickey y su «Prólogo» a la traducción de Andrómaca (1789)*
}

\section{A Woman's Voice in the Poetics of Neoclassical Tragedy: Margarita Hickey's «Preface» to her Translation of Racine's Andromaque (1789)}

\author{
Helena Establier Pérez \\ Universidad de Alicante \\ Helena.Establier@ua.es
}

ORCID iD: https://orcid.org/0000-0001-6503-367X

\section{RESUMEN}

En 1789, Margarita Hickey publica el primer volumen de sus Poesías varias, sagradas, morales y profanas o amorosas, donde incluye una versión propia de la Andrómaca raciniana (1667) que la convierte en la primera escritora española interesada por la traducción de la tragedia neoclásica, y también en la única dispuesta a aclimatar en España la obra del reputado dramaturgo francés. Pero además, ese volumen se abre con un interesante prólogo en el que la autora reflexiona sobre diferentes aspectos relacionados con el concepto de lo trágico y con la finalidad de la práctica teatral en su conjunto. Este trabajo analiza la contribución de Margarita Hickey al discurso teórico sobre la tragedia en un período en el que las directrices del «reformismo» neoclásico coexisten, no sin cierta tensión, con una concepción del espectáculo teatral más permeable a las exigencias populares y a los recursos propios de los nuevos modelos dramáticos.

Palabras Clave: Margarita Hickey; tragedia; neoclasicismo; Andrómaca; paratextos; Racine; traducción; poesías; escritura femenina; poética; teoría dramática.

\section{ABSTRACT}

In 1789, Margarita Hickey published the first volume of Poesias varias, sagradas, morales y profanas o amorosas, including her translation of Racine's Andromaque (1667). With Racine's version, Hickey became the first Spanish female writer interested in translating Neoclassical

* El presente trabajo se ha realizado en el marco del proyecto de investigación «BIESES. Escritoras españolas de la primera modernidad: metadatos, visualización y análisis», financiado por el Ministerio de Economía y Competitividad (FFI2015-70548-P). 
tragedy, as well as the only female who dared to translate the dramatic work of this reputed French playwright into our language. In addition, Hickey's work opens with an interesting preface in which the author reflects on different aspects related to the Neoclassical concept of tragedy and the purpose of drama. This paper analyses Margarita Hickey's contribution to turn-of-the-century theoretical discourse on tragedy, when the Neoclassical reformism has to coexist, not without some tension, with a conception of theater closer to the popular taste and more open to new dramatic models.

Key words: Margarita Hickey; Tragedy; Neoclassicism; Andromaque; Racine; Paratexts; Translation; Poems; Women's writing; Poetics; Dramatic theory.

En el marco general de reflexión y de debate sobre los géneros dramáticos que se inicia, aunque de forma un tanto aislada, con la primera edición de la Poética de Luzán (1737) y que va fraguando, con sus evidentes diferencias, desde mediados de la centuria hasta las primeras décadas del siglo siguiente ${ }^{1}$, la tragedia, con su halo erudito y su linaje clásico, siempre gozó de una posición

${ }^{1}$ El discurso teórico sobre la tragedia neoclásica se fue tejiendo intermitentemente durante la segunda mitad del siglo XVIII a lo largo de los diferentes «períodos evolutivos» del género (Cañas Murillo 2013, 89), desde el intento inicial de recuperación del clasicismo trágico a mitad de la centuria, a través del «neoclasicismo» más tarde en la etapa arandina, hasta el intento de revitalizar el género con propósitos ideológicos o políticos en la década final. Aunque en cada una de esas etapas el debate sobre la tragedia presenta matices propios relacionados con el contexto histórico-artístico, es interesante recalcar la permanencia a través de los años de la inquietud crítica acerca de la naturaleza, la composición y la finalidad del género, es decir, de «las reflexiones sobre lo esencial de la tragicidad» (Sala Valldaura 2005, 355). Los dos discursos sobre las tragedias españolas de Agustín de Montiano (Discurso I, 1750; Discurso II, 1753), por ejemplo, así como los capítulos IV y V del libro II del Compendio del Arte Poética de Antonio Burriel (1757) son buena muestra de esta actividad teórica sobre la tragedia ya hacia mitad del siglo XVIII. Desde entonces hasta la década de 1770, los debates sobre poética dramática son constantes, aunque las muestras prácticas de tragedia resulten escasas (García Menéndez 2002, 256) y su éxito comercial aún menor. En las postrimerías del siglo, la necesidad de adaptar la tragedia a los cambios éticos y estéticos así como a las novedades políticas (Fernández Cabezón 2012,107) propician que las disquisiciones teóricas cobren nuevos bríos, como se observa a través de los trabajos de José Quintana (1821), Pedro Estala (1793) Santos Díez González (1793) o Francisco Sánchez Barbero (1805). Según señala Roso Díaz en su estudio sobre el Pelayo de Quintana (1805), es este el momento de la consolidación de género, «cuando las piezas reflejan una poética madura y son instrumentos para la difusión de las ideas ilustradas» (2009, 606). La reedición de Las reglas del drama (1791) del mismo Quintana en sus Poesías de 1821, acompañada de nuevas e interesantes notas, confirma, por otro lado, que el asunto aún estaba vigente en las primeras décadas del siglo XIX. Es evidente, en cualquier caso, que como indica Sala Valldaura $(2005,357)$, ni se traduce igual ni se traduce lo mismo en la etapa arandina que en el cambio de centuria, y que también la reflexión teórica sobre la tragedia se va adaptando a las peculiaridades artísticas e ideológicas de cada período. Los estudios de Checa Beltrán (1996; 1998; 2003, 1534-1538) y de Rodríguez Sánchez 
distinguida. Mientras que en los años centrales del siglo los detractores y los defensores de las controvertidas comedias áureas, tan bien instaladas en el gusto popular, se enfrentaban encarnizadamente tratando de hallar una salida airosa al estancamiento de la escena nacional, las disensiones en los discursos sobre la tragedia procedían por lo general de cuestiones derivadas de la interpretación más o menos laxa de ciertos aspectos de la Poética aristotélica vinculados con la propia esencia del género. Se reflexionaba, por ejemplo, sobre la posibilidad de pergeñar fábulas «dobles» en las que determinados personajes evolucionaran desde el infortunio a la felicidad -dando cabida a las que López Pinciano $(2006,43)$ distinguió como tragedias «moratas» o de costumbres, con final reconciliador-, sobre la altura moral y social de héroes y personajes secundarios, sobre la conveniencia de volver a los argumentos antiguos en las tragedias modernas, sobre el auténtico sentido de la catarsis clásica (purgación $v s$. agitación de las pasiones) y en relación con ello, también acerca de la conveniencia de incluir el amor como motor trágico o de visibilizar los actos violentos en escena. Aunque el sustrato político-ideológico de la tragedia está también presente desde los inicios del debate teórico ${ }^{2}$, hacia finales de siglo este se concreta con nuevas cuestiones vinculadas a la deriva revolucionaria del país vecino, como el discurso sobre la finalidad «político-moral» (promonárquica) del género (véanse como muestra las opiniones de Estala o de Díez Gonzalez, bien estudiadas por Checa Beltrán), y/o con otras resultantes de la necesidad de «actualizarlo», bien atendiendo a los resortes que canalizaban de forma mayoritaria el gusto popular - la espectacularidad, lo melodramático, la emoción, la ternura o el patetismo, por ejemplo (Coca Ramírez 2000, 122)-, bien facilitando la fusión de tendencias (la nueva «tragedia urbana» distinguida por Díez González en Instituciones poéticas da buena cuenta de ello).

Si bien en sus dos conocidos discursos de 1750 y 1753 Agustín de Montiano y Luyando había ya reivindicado la tradición española de tragedias «con arte, y esplendor» $(1750,76)$, patrimonio que se venía reclamando aún al final

de León (1999) son imprescindibles para una revisión de los aspectos fundamentales de la poética trágica del Neoclasicismo y de su evolución a lo largo del período.

2 Checa Beltrán por ejemplo, explica cómo los textos tempranos de Montiano (1750 y 1753) y de Nasarre (1749) se inscriben «en aquella eclosión de patriotismo que los neoclásicos españoles escenificaron en un contexto político -el de los primeros años del reinado de Fernando VI- en el que la presión nacionalista se hizo difícilmente soportable para ellos, que ocupaban o aspiraban a ocupar cargos institucionales» $(2015,28)$. Sala Valldaura, por su parte, se refiere a Luzán como «el inspirador teórico de una tragedia centrada en la lección política» $(2006,457)$ y clasifica las tragedias neoclásicas de acuerdo con las variantes que presente el tema predominante en ellas, que es, en su opinión, el político: aquellas en las que predomina la defensa de la libertad frente al tirano (las anteriores a 1766), las que exaltan el regalismo o el absolutismo, las que impulsan el papel político de la nobleza y las que se centran en el derecho a la libertad individual ya en los albores del XIX (2006, 119-120). 
del siglo (Estala 1793, 48), lo cierto es que el reconocimiento del magisterio francés en este particular fue unánime. Por ello, mientras unos pocos -como Luzán, el propio Montiano, Nicolás Fernández de Moratín, López de Sedano, Trigueros, etc.- ensayaban entre 1750 y 1770 la composición de tragedias españolas (Berbel 2003; Sala Valldaura 2006), muchos más trataban de rellenar este vacío original con la traducción/adaptación/imitación de obras extranjeras -sobre todo francesas, aunque también italianas- en la cantidad y con las variantes que ya nos han venido explicando diversos e imprescindibles trabajos sobre el particular (García Garrosa y Lafarga 2004 y 2009; Lafarga 1983-1988, 1997, 1999, 2004, 2013; Ríos Carratalá 1997; Urzainqui 1991).

Sabemos, pues, que este fue un asunto primordial en la política teatral de la generación arandina y de la época de Olavide, desvelo que se refleja a lo largo de la segunda mitad del siglo en la preocupación teórica por cómo «nacionalizar» la tragedia gala, cómo adaptarla al panorama hispánico manteniendo su elevación y su espíritu aleccionador sin vulnerar la idiosincrasia nacional. Los principios básicos de la tragicidad útil y ejemplarizante eran, desde luego, compartidos por cuantos se asomaron al discurso teórico sobre el género tanto desde el ámbito de la creación original como desde el de la traducción; sin embargo, el escaso reconocimiento de la labor de los traductores y las dificultades consustanciales al ejercicio de trasladar una obra de un ámbito literario-cultural a otro, generaron debates colaterales a los citados más arriba para la creación original: controversias, por ejemplo, sobre la opción metodológica a la hora de traducir (literalidad/fidelidad/libertad), sobre las vías de adaptación a los usos dramáticos españoles (preferencia por la división en tres actos, transformación de los pareados consonantes en verso suelto o romance endecasílabo, etc.), sobre el polémico trabajo del traductor (méritos y dificultades), sobre las consecuencias de su labor en la sociedad y en la cultura de destino (perjuicios al idioma, beneficios pedagógicos o literarios...), etc. ${ }^{3}$

Exceptuando las «poéticas» en volumen que estudiaban de forma específica el género trágico, como las de Luzán y Burriel, o la de Díez González ya al final del siglo (1793), lo cierto es que el grueso de la reflexión teórica sobre el particular discurrió a través de discursos y ensayos breves, bien en el marco de volúmenes colectivos -como el texto de Francisco Guerra (1764) «en el que se prueba ser más útil la Tragedia, que la Comedia, para civilizar e ilustrar una Nación», incluido por Nipho en sus Discursos eruditos de varios ingenios es-

${ }^{3}$ Sobre la valoración de la traducción en el siglo XVIII y su papel renovador en el panorama teatral español contamos ya con magníficos y numerosos estudios, especialmente por parte de Francisco Lafarga $(1997 ; 2004,213-241 ; 2013)$ y de María Jesús García Garrosa y Lafarga (2004 y 2009). En estos trabajos -bien conocidos y fundamentales tanto a la hora de comprender el significado de las traducciones como de seguir los debates intelectuales que estas generaron- hallamos un magnífico y prolijo estado de la cuestión, que omitimos pues aquí. 
pañoles - o sueltos, como Las reglas del drama (1791) de Quintana y también desde los principales diarios de la capital, tales como El pensador matritense, el Memorial literario, el Correo de Madrid o el Diario de Madrid, por ejemplo4.

Pero el auténtico meollo de la reflexión sobre la tragedia se gestó en el aparato paratextual (advertencias al lector, prólogos, prefacios, posfacios, informes de censura y demás) que acompañaba a las obras originales, traducidas, adaptadas o meramente «inspiradas» en modelos extranjeros. Los ya citados discursos de Montiano ante su Ataúlfo y su Virginia abrieron la veda para que Juan José López de Sedano (1763), Pedro de Silva (1764), Juan Francisco del Postigo (1765), Tomás Sebastián y Latre (1764, 1772), Ignacio García Malo (1788), Tadeo Moreno González (1788), Mariano Luis Urquijo (1791) o Pedro Estala $(1793)^{5}$, entre otros, introdujeran sus tragedias reflexionando sobre algunas de las ya citadas cuestiones - de naturaleza técnica o ideológica- que sustentaban el debate sobre este género. En este listado de consideraciones sobre la tragedia que se producen entre la primera edición de la Poética de Luzán y el final del siglo, no se desliza más que una rubricada con nombre femenino: el «Prólogo» de Margarita Hickey y Pellizoni al primer -y único- volumen de sus Poesías varias, sagradas, morales y profanas o amorosas (1789), donde hallamos, precediendo a las anunciadas composiciones poéticas, la traducción realizada por la propia autora de la Andromaque (1667) de Racine.

La singularidad de la labor de Hickey en el campo de la tragedia neoclásica merece, sin duda, una mayor atención de la que ha recibido hasta el momento. Sobre los avatares biográficos de esta escritora de origen franco-italo-irlandés, nacida en 1728 en Palma de Mallorca y fallecida probablemente hacia 1801 en la capital, contamos ya con varios trabajos que nos han permitido forjarnos un cierto perfil ideológico e intelectual de ella. Por las pesquisas de Sullivan (1997) y posteriormente de Pierucci (2006), sabemos de su matrimonio en 1744 con el noble navarro Juan Antonio de Aguirre, que se hallaba al servicio de la Corona borbónica (Pierucci 2006, 16), del fallecimiento del único hijo biológico de ambos y de la adopción posterior de una niña con quien, según se deduce del testamento de la autora, no guardaba una relación cálida en 1801 , fecha en la que, poco antes de fallecer, Hickey se declara novicia de la Orden Tercera de los Franciscanos (Sullivan 1997, 223-227).

Sabemos también, a través de los estudios de Deacon (1988) y de Ríos Carratalá (1984, 1987), que mantuvo una firme amistad con García de la Huer-

${ }^{4}$ Para el estudio de la prensa como medio fundamental en la difusión del discurso teórico sobre la tragedia, fuera a través de anuncios de novedades editoriales, de prospectos de suscripción, de opiniones críticas sobre obras traducidas, de críticas teatrales, de disertaciones sobre la esencia y las dificultades de la traducción o de ataques a quienes la realizaban, remitimos a Qualia (1939, 184-211), Urzainqui (1997, 53-59) y a la introducción al volumen de García Garrosa y Lafarga (2004, 66-72).

5 Ver la sección final de Bibliografía citada. 
ta, de la cual dan cuenta tanto las cercanas cartas que se enviaron en 1766 después de la marcha del extremeño a París como los sonetos que ambos se cruzaron antes o después de la vuelta del escritor a España tras su destierro en Orán (1777-8), y que aparecen recogidos en las Poesías varias de Hickey. Tenemos constancia asimismo de su relación con Agustín de Montiano, a quien envió las traducciones de sus primeras tragedias antes de 1759 -fecha en que, como veremos, este le remite a la autora unas cartas muy elogiosas sobre sus versiones de Andromaque y de Zaïre-, y posiblemente con el Marqués de Valdeflores, Luis José Velázquez, de cuya adversa suerte Hickey da buena cuenta por carta a García de la Huerta tras el Motín de Esquilache (Deacon 1988, 405), de manera que los vínculos de la escritora con algunos de los insignes miembros de la Academia del Buen Gusto parecen claros.

De los diversos documentos que guarda el Archivo Histórico Nacional sobre la actividad editorial de Hickey, deducimos que su primer movimiento público para afirmarse como escritora no se produjo hasta 1779, cuando ya era viuda, momento en el que -entre los meses de abril y julio- solicitó licencia para imprimir las obras que diez años más tarde compondrían el primer volumen de sus Poesías varias (Andrómaca, Diálogo en verso entre la España y Neptuno y las composiciones líricas originales) ${ }^{6}$. Lo hizo bajo un seudónimo, el de Hernanda de la Oliva, que ocultaba a una escritora aún temerosa de su osadía literaria y consciente de la debida modestia femenina. Las tres obras recibieron informe favorable de Nicolás Fernández de Moratín, pero no llegaron a ver la luz.

De hecho, ocho años más tarde, en 1787, volvió a dirigirse a Carlos III para solicitar licencia de impresión, esta vez de dos tomos de Poesías sagradas y profanas, que comprendían tres tragedias en traducción (Andrómaca y Zayra, ahora ambas en verso octosílabo, y la Alcira de Voltaire en endecasílabos ${ }^{7}$ ), unos Discursos «muy instructivos sobre el drama» ${ }^{8}$, dos poemas en elogio del Capitán General D. Pedro Ceballos y unas poesías líricas originales.

A través del citado informe de censura -favorable- de Casimiro Flórez Canseco, fechado el 16 de octubre de 1787, sabemos que hacia mitad de siglo Hickey ya había realizado sendas versiones de la Andrómaca de Racine y de Zayra de Voltaire en verso alejandrino -siguiendo los originales franceses-, y que de ellas había informado elogiosamente Agustín de Montiano a la autora

${ }^{6}$ Dichos expedientes se encuentran en el Archivo Histórico Nacional (AHN), Consejo de Castilla, Impresiones, Leg. 5544, Exp. 59.

7 De Alcira no tenemos ni rastro; la primera versión de Zayra en alejandrinos se encuentra manuscrita en la Biblioteca Nacional con correcciones de Eugenio de Llaguno, según afirma Pascual de Gayangos en nota autógrafa inicial (MSS/18549/5 y MSS.MICRO/10455).

8 «Censura de Don Casimiro Flórez Canseco a las Poesías sagradas y profanas de Doña Margarita Hickey». Archivo Histórico Nacional, Consejos, Consejo de Castilla, Impresiones, Leg. 5553, Exp. 76. 
por vía epistolar en $1759^{9}$. Quizá el triunfo de la adulterada versión de la $A n$ dromaque compuesta por Pedro de Silva, que comenzó a circular poco después por los teatros de la capital con el heroico título de Al amor de madre no hay afecto que le iguale, o el éxito de La Zayda de Olavide, que se editó en diversas ocasiones y se llevó a las tablas sin descanso en Barcelona y Madrid entre 1771 y 1794 (Lafarga 1982, 170; Andioc y Coulon 1996, 882), fueran un estímulo para que Hickey se decidiese a desempolvar tres décadas más tarde sus dos tragedias de 1759 y a traducir otra nueva; al menos, así lo reconoce la propia autora para la tragedia de Racine en su «Prólogo» a la edición de Poesías varias de 1789, el cual, según señala el informe de Florez Canseco, acompañaba ya al manuscrito presentado al Consejo en 1787.

En dicho expediente de censura, el helenista Flórez Canseco informa favorablemente de todas las obras presentadas por Hickey: de los poemas, de las dos cartas de Voltaire que no nos han llegado y, por supuesto, las tres traducciones teatrales. Así, el 24 de octubre de 1787 se concede la preceptiva licencia, y dos años más tarde, en 1789, aparece por fin en la Imprenta Real de Madrid el primer volumen (y único, finalmente) de las Poesías varias de Hickey, firmadas por «una dama de esta corte»e incluyendo solo los tres textos para los que ya había obtenido permiso de impresión en 1779: Andrómaca, Diálogo en verso entre la España y Neptuno con motivo del fallecimiento del Capitán General D. Pedro de Cevallos y diversas poesías.

El título de la portada, sin embargo, anunciaba también el contenido del segundo tomo previsto. Por lo que allí se indica, aquel debía de incluir otro poema épico en elogio del Capitán General don Pedro Cevallos, dos tragedias francesas más (seguramente las citadas Zaira y Alcira, valoradas por Flores Canseco), varias piezas en prosa de otros autores y algunos discursos sobre el drama «muy curiosos e instructivos» (los ya citados de Voltaire).

Dicho segundo volumen nunca resultó impreso, con lo cual las citadas tragedias volterianas, aun con su licencia de impresión, quedaron sin ver la luz. Es más que probable que los acontecimientos históricos de aquellos meses tuvieran una incidencia directa en los avatares editoriales de la obra de Hickey. $\mathrm{Si}$ atendemos a la fecha en la que el Memorial Literario da noticia de la publicación del primer volumen de Poesías varias, noviembre de 1789, esta coincidió con el despliegue de medidas destinadas a detener el pensamiento revolucionario francés, que, como es bien conocido, alcanzó el cierre de fronteras, el control de extranjeros, la persecución de simpatizantes del proceso que vivía el país vecino o de cualquier forma de difusión de las ideas «burguesas»

${ }^{9}$ La carta de Montiano sobre Andrómaca la incluye la autora entre los textos preliminares a su edición de Poesías varias de 1789 (Hickey 1789, XV-XVI). De la carta sobre Zayra sabemos a través del informe de censura redactado por Flórez Canseco en 1787 (ver nota 12), ya que la traducción de Voltaire realizada por Hickey quedó, como indicaremos, inédita. 
vencedoras en él, con el consiguiente recrudecimiento de la censura, la desaparición de prestigiosos periódicos, el resurgir de publicaciones reaccionarias y la incautación de cualquier documento susceptible de agredir a la religión o a la monarquía (Herr 1964, 201).

Sabemos sobradamente, tal y como nos explicó Lafarga (1982), que la fortuna institucional de Voltaire en la segunda mitad del XVIII español, pese a la gran difusión de sus obras, no fue excesiva, y es lógico que, no siendo tradicionalmente un autor caro al pensamiento «oficial» español, sus obras se hallaran especialmente controladas a finales de 1789, precisamente en el momento en que la Imprenta Real preparaba la impresión del segundo volumen de las Poesías de Hickey, con las dos traducciones del «filósofo impío» y alguno de sus discursos sobre el teatro.

De hecho, la década siguiente no fue propicia ni para la difusión de la literatura volteriana en nuestro país ni para las inquietudes intelectuales de Hickey, quien, al ser tajantemente denegada en 1791 su solicitud de impresión del tratado en verso Descripción geográfica e histórica del orbe ${ }^{10}$, no volvió a incurrir en el terreno literario.

Su primera y única obra publicada, por tanto, es el volumen I de sus Poesías varias cuando la autora contaba ya 61 años. Este primer tomo comprendía, tal como hemos señalado anteriormente, su traducción de la tragedia Andromaque (1667) de Racine, un Diálogo en verso entre España y Neptuno en elogio del Capitán General D. Pedro de Ceballos y una cantidad nada desdeñable de composiciones poéticas que ella misma, en el título completo de su obra, describía como "sagradas, morales y profanas o amorosas»" ${ }^{11}$.

Lo cierto es que del estudio de sus poesías -que, pese a algunos desaires críticos, constituyen una muestra tan relevante como meritoria del escaso quehacer literario femenino en el XVIII-, se han ocupado Salgado (1992, 1994), Zorrozua (1999) y ampliamente Pierucci en su reciente y única edición actual de las mismas (2006, 32-69). Sin embargo, la contribución de Hickey a la

${ }^{10}$ La Descripción geográfica e histórica del orbe en octosílabos fue rechazada sin contemplaciones en enero de 1791 por la Real Academia de la Historia. Las censuras, de Tomás López y Joaquín Juan de Flores, se encuentran en la RAH (Colección Censuras, Legajo 10, n. 35. 1 M-RAH, 11/8022(35). Resulta difícil saber en qué medida el intento de Hickey de difundir apenas dos años antes dos traducciones del cuestionado e impío Voltaire, pudo influir en el juicio de los censores de la Real Academia de la Historia. ¿O acaso incomodaría a los Académicos la pretensión de Hickey de sobrepasar los límites implícitamente consentidos para la actividad intelectual femenina, abandonando los campos de la traducción y de la creación poética para incurrir en terrenos vedados como la erudición o la ciencia? ¿Serían acaso las severas censuras obtenidas por Hickey una lección y un preventivo para la incómoda «bachillería» femenina tan denostada en el XVIII?

${ }^{11}$ El volumen fue bien acogido por la crítica; de hecho, el Memorial Literario de noviembre de 1789 lo estimaba como valiosa muestra de la instrucción de la autora y de su talento para la poesía (XVIII: 342 ). 
tragedia neoclásica, tanto por la vía de la traslación de los modelos franceses al ámbito nacional como por la reflexión que realiza sobre las bases ideológico-estéticas del género, no ha suscitado hasta el momento gran interés, a pesar de tratarse de un ejercicio absolutamente inusual en pluma femenina. En las páginas siguientes nos centraremos en su traducción de Andrómaca, única conservada impresa, y especialmente en el interesante «marco» paratextual con el que la autora la arropa.

Conviene señalar en este punto que la actividad de las mujeres en el ámbito, ya de por sí limitado, de la tragedia neoclásica $-\mathrm{y}$ en general en el del teatro de la época-, es escasa y, sobre todo, bastante tardía. De hecho, exceptuando las obras de Margarita Hickey, las muestras fundamentales de actividad femenina original o en traducción en el campo de la tragedia corresponden a las postrimerías del XVIII o incluso a los inicios del XIX, tal como se desprende de las páginas que le dedican al asunto Palacios Fernández en su esclarecedor estudio sobre la mujer y las letras en el siglo XVIII (2002, 191-233) y Zorrozua en su ya citada tesis doctoral (1999, 437-507). Así, fue probablemente en la última década del siglo cuando María Martínez Abello escribió su tragedia original La Estuarda, que no está fechada y que aparentemente no llegó a representarse en función pública (Establier Pérez 2017, 771-793). En esos mismos años, concretamente en 1801, María Rosa de Gálvez, la dramaturga más conocida del período, llevó a las tablas de forma excepcional dos de sus obras trágicas, Safo y Ali-Bek, mientras que el resto se publicaba dentro de sus Obras Poéticas en 1804. Un año antes, en 1803, había traducido Magdalena Fernández y Figuero la tragedia francesa La mort d'Abel, de Gabriel Legouvé, con el título La muerte de Abel vengada.

Es evidente, a la vista de los escasos ejemplos citados, que la carga ideológica consustancial a la tragedia neoclásica -su permanente reflexión sobre el poder, su voluntad de representación del conflicto entre tiranía y libertad, su defensa del papel político de la nobleza, del absolutismo y del regalismo, etc.-, quedaba fuera, de forma tácita, de las expectativas generadas por las limitadas incursiones femeninas en el ámbito dramático. Por ello, fueron muy pocas las escritoras con arrestos suficientes para incursionar en un género que requería un bagaje cultural y un fondo ideológico escasamente acordes con las convenciones dieciochescas acerca de la naturaleza femenina y con los roles de género asignados a las mujeres. Y por eso también, las - pocas- obras citadas antes responden ya a la mixtificación del género trágico que se produce en las últimas décadas del XVIII y, o bien se enmarcan en géneros «híbridos» como el drama trágico o el melólogo, o bien están impregnadas de lo lastimoso (lo emotivo/lo sentimental), que, siendo un ingrediente constitutivo fundamental de la producción teatral del cambio de siglo, también encajaba mejor con los intereses de las escritoras finiseculares y con el estereotipo de género en el que estas se reconocían.

Observemos que ninguna de las obras consignadas, salvo las de Hickey cuyas primeras versiones, ya lo hemos señalado, son anteriores a 1759-, se 
enmarca en el período de introducción y adaptación de la tragedia neoclásica al ámbito dramático español (entre 1750 y 1770), es decir, en la época cumbre de la reforma del teatro, que incluye la actividad teórica y los primeros ensayos en el género trágico de los miembros de la Academia del Buen Gusto y aledaños, los Desengaños al teatro español de Moratín padre, etc., y la práctica teatral de la generación arandina. A la luz de esto, Hickey destaca no solo por ser la primera -y única- escritora española interesada por la traducción y adaptación de la tragedia neoclásica, asunto de orden capital en la política teatral dieciochesca, sino además, por haber ofrecido la más temprana versión española de la Andrómaca raciniana en los mismos años en los que comenzaban a traducirse las obras del dramaturgo francés en nuestro país.

De hecho, aunque hacia 1715 Cañizares ya realizó una adaptación aislada -y nada neoclásica- de la Iphigénie en Aulide raciniana (El sacrificio de Efigenia) en un primer momento de fomento del drama ajustado a las reglas, es en la década de los cincuenta cuando algunas obras del dramaturgo francés obtienen auténticas traducciones a nuestro idioma: de 1752 es, por ejemplo, el Británico en prosa del académico Juan de Trigueros (bajo el seudónimo de Saturio de Iguren), y de 1754 la Atalía en verso de Eugenio de Llaguno, futuro secretario de la Academia de la Historia, obras ambas muy alabadas por Luzán en su Poética (1977, 410-411). De las dos décadas siguientes son ya las primeras traducciones -más o menos fieles- y adaptaciones de otras obras de Racine, como la imitación de Esther y Athalie realizada por López de Sedano en su Jahel (1763), la traducción Iphigenia (1769) de Jovellanos -recientemente descubierta-, las versiones de Phèdre del académico Pedro de Silva (s.a.) y de Pablo de Olavide (representada en 1788 pero escrita mucho antes), y la de Mithridate (s.a.) realizada por este último autor ${ }^{12}$.

Es en la estela de estos afanes eruditos por aclimatar al maestro francés donde conviene ubicar la primera traducción de Andromaque realizada por Hickey antes de 1759. Resulta evidente que Racine era un autor lo suficientemente prestigioso entre los defensores de la ideología ilustrada (Tolívar Alas 1995, 60-61) como para justificar, simplemente citando su nombre en la portada de las Poesías varias, la elección de la traductora. Desde el reconocimiento que le brinda Luzán -junto a Corneille y a Molière- en su Poética y en sus Memorias Literarias de París $(1751,74)$, la admiración por el «Eurípides de Francia» (Luzán 1977, 411) y la reivindicación de su magisterio se hacen evidentes en los ensayos teóricos que abordan el asunto de la tragedia francesa $-y$ en especial la raciniana- como modelo ideal de la práctica teatral nacional hasta bien entrado el siglo siguiente ${ }^{13}$, aunque ello no se refleje necesariamen-

12 Qualia (1939), Martínez Cuadrado (1995) y Tolívar Alas (1984, 1995, 2001) se han ocupado de la recepción de Racine en la España del XVIII.

13 Véanse, por ejemplo, la advertencia «Al público» con la que abre su versión en verso de Británico (1764) Tomás Sebastián y Latre, el discurso de Mariano Luis Urquijo 
te en el número de traducciones de las obras del escritor francés. Entre ellas, $F_{e d r a}{ }^{14}$ y Andrómaca fueron las acogidas con mayor calidez en nuestro país, entre otras razones por la fuerza trágica que comparten ambas heroínas.

De hecho, y por lo que atañe a la última de las dos obras citadas, en las tres décadas que median entre la primera traducción de Hickey - bien acogida por Montiano en 1759, pero nunca editada- y la publicación de la Andrómaca asonantada en la edición de 1789 (que no nos consta se representara) ${ }^{15}$ son varias $-\mathrm{y}$ bien distintas entre sí- las versiones del asunto tratado por Racine que se vieron o leyeron en el territorio nacional, desde aquellas que perseguían la difusión y el aplauso popular, como la libérrima, «heroica» y exitosísima del académico Pedro de Silva (Al amor de madre no hay afecto que le iguale) o el melodrama Andrómaca en un acto de Luciano Comella, hasta las que se pensaron para públicos más reducidos ${ }^{16}$. Hickey es la única, en cualquier caso,

que acompaña la traducción de La muerte de César de Voltaire (1791) o las notas que Quintana (1821) añade a la nueva edición de Las reglas del drama.

${ }^{14}$ Sobre la recepción de Phèdre en la España del XVIII, toda la información en Tolívar Alas (1991).

15 Andioc y Coulon especulan con que la Andrómaca representada durante tres días seguidos en diciembre de 1789 (del 19 al 21) por la compañía de Ribera en el Teatro de la Cruz pudiera ser la de Hickey o la de Clavijo y Fajardo (1996, 418 y 624). Descartan sin embargo que se tratara de la versión más popular de Silva, al hallarse esta -dicen- en manos de otra compañía. No obstante, como muestra el Diario de Madrid en sus números del 5 al 8 de junio de 1788, la Andrómaca de Silva (que también recibió el título de Al amor de madre no hay afecto que le iguale; la Andrómaca) fue efectivamente llevada a las tablas por la Compañía de Ribera. Por otro lado, la tragedia de Clavijo, realizada en la década de los setenta para los Reales Sitios, sería difícilmente recuperable para la escena pública a finales de siglo.

En resumen, es más que probable que la «comedia de teatro» Andrómaca representada en diciembre de 1789 fuese la de Pedro Silva, y seguimos por tanto sin tener constancia de que la tragedia de Hickey -mucho más ajustada a la preceptiva neoclásica y menos atractiva para el público- llegase a las tablas.

${ }^{16}$ Además de la versión archiconocida de Silva, a la que nos referiremos más adelante, una Andrómaca en un acto de Luciano Comella con música instrumental se representó en diversas ocasiones entre 1796 y 1802 (Andioc y Coulon 1996, 624). Además de estas, hubo una versión de Tadeo Moreno González en tres actos (El Axtianacte de 1788), que se conserva manuscrita en la Biblioteca Nacional y que aparentemente no llegó a editarse ni a representarse, y que, tal y como refiere el propio autor en la introducción a la obra («Motivo de la composición desta pieza») fue escrita para una compañía de aficionados de la Corte. Según explica Cotarelo, hubo otra versión de José Clavijo y Fajardo, quien, apenas fue nombrado director del teatro de los Reales Sitios, «se apresuró a traducir para él la Andrómaca, de Racine» (1897, 68-69). Por último, en la Biblioteca de la RAE se conserva también un manuscrito de Andrómaca en cinco actos traducida por A. de S. (Antonio de Saviñón), probablemente de principios del XIX.

Circulaba, por otro lado, una pieza «de teatro» o «heroica», de título Andrómaca, y Pirro, representada en diversas ocasiones por la compañía de Ribera en las dos últimas décadas del siglo con participación de Rita Luna. Pudiera ser la de Silva, que, como hemos 
que se declara traductora de Racine, y su versión es, de hecho, la más fiel de cuantas nos legó el siglo XVIII.

Pero además del prestigio autorial, la obra ofrecía sin duda unos atractivos que no podían pasar desapercibidos a la mirada femenina de la autora. La heroína trágica resultante de la reinterpretación del mito clásico realizada por Racine, encarnación de la fidelidad conyugal y de la aflicción, víctima y cautiva, presionada tanto por la incontinencia amorosa de Pirro como por sus propios deberes políticos y familiares, triunfante al fin y convertida -honor intacto- en flamante reina de los griegos, era, sin duda, un aliciente de lo más tentador para las ambiciones literarias de Hickey ${ }^{17}$. De hecho, al distanciarse de la tradición clásica de Eurípides (Las troyanas, Andrómaca) prolongando la vida de Astianax -hijo de Andrómaca y del difunto Héctor, y heredero por tanto de la corona troyana-, Racine traspasó el desafío político para dar alas a un dilema femenino ${ }^{18}$ que encandilaría no solo al público francés de su tiempo sino también a los espectadores -y espectadoras- españoles del último tercio del setecientos: aceptar como esposo a Pirro, artífice de la hecatombe de Troya y salvar así la vida del niño Astianax, único heredero de la dinastía de Héctor, o bien negarse, preservando el honor -el suyo, el de su esposo y el de los troyanos vencidos-, pero sacrificando a cambio a su propio hijo y por ende el futuro de la monarquía.

Ese dilema trágico entre el bien común y el deseo individual -tan conmovedor, pero al tiempo tan acorde con los gustos del neoclasicismo español-y

indicado, fue llevada a las tablas por la misma compañía con otro título (Al amor de madre no hay afecto que le iguale). La compañía de Luis Navarro representó también en esos mismos años otra Andrómaca y Pirro «de teatro», tal y como anunciaba el Diario de Madrid el 18 de noviembre de 1788 (2098).

${ }^{17}$ En su interesante trabajo sobre las posibles «fuentes» de la Andrómaca raciniana, Forestier pasa revista a las ya conocidas, desde las clásicas -la Eneida, que el propio autor cita en su prefacio a la obra, Eurípides a través de Andrómaca y de Las Troyanas, Las Heroidas ovidianas- hasta las setecentistas, como Pertharite (1651) de Corneille o Hercule mourant (1634) de Routrou, para apuntar que el éxito de Racine pasa por ofrecer una intriga totalmente nueva, manejando y disponiendo los datos que le aportan sus variadas fuentes para construir una historia coherente con la experiencia de las relaciones humanas y sociales (reales y literarias) del público de su tiempo $(1998,50)$. Es evidente -no tanto por la adaptación de Hickey, que no llegó a las tablas, pero sí por otras como la citada de Silva- que un siglo después, esta historia de la princesa cautiva a la que se intenta hacer ceder por presiones morales, seguía entusiasmando.

${ }^{18} \mathrm{Y}$ es que el «dilema»-como ocurre, por ejemplo, en La Mariane de Tristan L' Hermite o en $\mathrm{Le}$ Cid de Corneille- es el elemento clave de la tragedia clásica francesa (Forsyth 1983, 54). El dilema que plantea Racine en Andromaque, desconocido por las fuentes antiguas, es, de hecho, digno de Corneille, y como señala Natan, «il permet à Racine d'inventer une intrigue apte à rivaliser avec les plus grandes tragédies» $(2013,247)$. Sobre las fuentes contemporáneas de Racine en relación a este «dilema» que sustenta su Andromaque, ver Rohou (2000). 
la favorable resolución del mismo que pergeñó Racine al salvar en todos los sentidos a la madre, al hijo y a la institución monárquica, habían sin duda de presentarla como una obra especialmente conveniente a los ojos de los adaptadores españoles y gratificante para su público. Pero además, el que esa disyuntiva raciniana descansara sobre hombros femeninos, el hecho de que el ramillete de valores y bondades que da pie a la favorable resolución del conflicto (fidelidad conyugal, celo familiar, defensa del bien común, etc.) se concentrara en una heroína que resultaba triunfante y recuperaba el estatus perdido, no podía dejar de cautivar a una escritora como Hickey, especialmente sensible, como bien deja ver en algunos de sus poemas, a los desequilibrios de género ${ }^{19}$, y consciente también de la prudencia que requería la incursión femenina en un ámbito literario, el del teatro trágico, que era feudo de los varones. Frente a las Medeas coléricas y las Cleopatras suicidas que ofrecía la tradición trágica clásica, la Andrómaca raciniana era un modelo femenino de valores, virtud, heroísmo y dignidad monárquica que, respondiendo a la perfección a los dictados de la preceptiva española sobre la tragedia neoclásica, contribuía a legitimar la osadía traductora de Hickey.

Así, respaldada por el prestigio del tema clásico ${ }^{20}$, por la autoridad de Racine y por la firmeza ideológica -en lo personal y en lo político- de la heroína por él propuesta, Hickey se atreve a traer a suelo patrio la tragedia que consagró la carrera dramática del autor francés y a proponerla, como bien nos muestra su prólogo, como modelo de utilidad y buenas costumbres para la discutida dramaturgia nacional. Trataremos, en consecuencia, de resaltar a continuación el doble valor de este discurso paratextual, tanto en el conjunto de la reflexión teórica sobre la tragedia neoclásica como en el proceso -aún titubeante- de afirmación de una posible autoridad intelectual femenina.

Las Poesías varias aparecen, efectivamente, precedidas de un breve «Prólogo», que constituye en su práctica totalidad una reflexión sobre la traducción

${ }^{19}$ Con gran claridad reclama, por ejemplo, en la última de las composiciones recogidas en sus Poesías varias («Remitiendo a un conocido estas poesías»), el cuestionado numen poético femenino y la igualdad de los sexos en el ámbito de la creación: «Porque esto, Danteo,/ solamente ha sido/ querer hacer prueba/ por gusto o capricho;/ De si el delicado/ sexo femenino,/ a pesar de necios/ y vulgares dichos,/ Quando se le antoja/ puede dulces himnos/ cantar a la Lira/ de Apolo divino:/ Y habiendo tocado,/ comprobado y visto/ que si Delio influye,/ cualquiera es lo mismo;/Y que si él no asiste/ por más masculinos/ que sean, arrogantes/ y desvanecidos,/ Jamás en la cumbre/ del glorioso Pindo/ lograrán mirarse/ los más presumidos» $(1789,425)$.

20 Para un estudio de la presencia de historia y de los mitos grecorromanos en las tragedias neoclásicas españolas (Virginia de Montiano, Agamenón vengado de García de la Huerta, Ifigenia en Áulide y Ciane de Siracusa de Trigueros, etc.), ver Nieto Ibáñez (2004, 305-331). Sobre la Iphigenia de Jovellanos, ver la edición de 2007 y los estudios que la preceden. De la anónima Polixena (1799), hija de Príamo y víctima de la guerra de Troya, se ha ocupado recientemente Cañas Murillo (2010). 
de la Andrómaca realizada por la autora, y a través de aquella, sobre determinados aspectos relacionados con el concepto de lo trágico y con la finalidad de la práctica teatral en su conjunto. A este respecto, no pasa desapercibido que si bien las poesías líricas integran las dos terceras partes del volumen (162-426), solo las últimas líneas del discurso preliminar de Hickey se dedican a presentar sucintamente estas composiciones, en las que dice haber «divertido a veces su genio y ociosidad, o falta de ocupaciones y de diversiones adaptadas a mi gusto» (XIV). A tenor de la ligereza con la que valora su copiosa actividad lírica frente a las prolijas explicaciones que ofrece sobre su traducción de la Andrómaca, no es difícil colegir en qué dirección se orientan las inquietudes literarias de la autora, y en consecuencia, también sus esfuerzos paratextuales.

Parece conveniente destacar en este punto un aspecto que distingue el prólogo de Hickey de otros ejercicios discursivos dieciochescos que funcionan como marco autorial para la labor literaria de las mujeres: el constante ejercicio de afirmación de autoridad femenina que atraviesa las diez páginas que componen el texto de la autora. La conciencia de transgresión, de invadir un territorio hostil a la presencia de las mujeres, es un denominador común a la práctica literaria femenina en el XVIII, que se traduce paratextualmente no solo en el empleo sistemático de los tópicos retóricos al uso (humilitas, captatio benevolentiae, etc.), sino también en la ambigüedad con la que las escritoras/ traductoras suelen abordar el sustrato de su labor, eludiendo los discursos puramente teóricos en los que se requiere un posicionamiento autorial sobre diferentes aspectos del texto literario, y ofreciendo en su lugar justificaciones varias sobre las motivaciones -por lo general, extra-literarias- de la tarea emprendida, sobre su capacitación o su derecho a expresarse públicamente, o sobre el potencial pedagógico-moral de la obra publicada.

Frente a ello, el prólogo que escribe Margarita Hickey para sus Poesías varias revela, como veremos, un talante escasamente dado a la modestia femenina, que ni disfraza sus motivaciones literarias ni vacila a la hora de sentenciar sobre aspectos en los que la autoridad de las mujeres era nula hasta el momento, como el método para traducir o las reglas del arte trágico. De hecho, no hay rastro en este prólogo de las declaraciones al uso de modestia femenina (la clásica petitio benevolentiae fundamentada en la torpeza «mujeril» de la traductora o en su falta de instrucción literaria), ni tampoco otros ejemplos convencionales de manejo del tópico de la humilitas en los prólogos de obras traducidas por mujeres, que suelen justificar su labor en el afán de complacer al otro -responder a una petición expresa de un familiar o conocido de prestigio- o incluso, en el caso de las traducciones, en el deseo de realizar un ejercicio «escolar» de práctica del idioma.

Bien al contrario, las primeras líneas del prólogo de Hickey recogen la siguiente declaración de la autora sobre la razón que impulsa sus versiones dramáticas: «Hace algunos años que, deseando ver cómo parecerían y si agra- 
darían en España las Tragedias, compuestas en el gusto y método Francés (tan celebradas en las demás Naciones), emprendí traducir dos...»(III).

Sorprende que el motivo aducido para su traducción sea, en primera instancia, de «política dramática», poco habitual en los paratextos de las dramaturgas del periodo pero perfectamente coherente con el debate sobre la necesidad de renovación de la escena nacional que se mantiene de forma intermitente a lo largo de la segunda mitad del siglo, y también el que la autora no pierda ocasión de apuntar hacia sus propias inquietudes intelectuales como incentivo fundamental de su labor. Inquietudes que no se vieron colmadas, por cierto, por ninguna de las numerosas piezas trágicas traducidas del francés y del italiano -como las de Metastasio, señala- que se estrenaron en los teatros en los mismos años en que ella solicitó el dictamen de Montiano, y que la disuadieron en aquel momento de dar su obra «a una de las compañías de cómicos de esta corte» (V). Insatisfacción ante el teatro trágico de su tiempo, curiosidad intelectual y estímulo ajeno; he ahí las claves de la decisión de hacer pública, al menos dos décadas después, su versión dramática «a impulsos de aquella misma curiosidad, que aún subsiste en mí, y a persuasiones de algunas personas que se hallan movidas de la misma, me he determinado por fin a dar al público la Andrómaca del celebrado Racine» (VI).

Aunque hacia el final de su prólogo Hickey termine enarbolando la preceptiva bandera femenina de la moralidad/utilidad para refrendar las bondades de su procedimiento de traducción y del resultado del mismo ${ }^{21}$, conviene destacar por inusual entre nuestras escritoras dieciochescas la abierta declaración de iniciativa personal y de criterio dramático con la que abre su discurso paratextual.

Bien al contrario, ampararse en la auctoritas masculina, como hace a continuación Hickey al indicar que remitió su traducción de Andrómaca a Agustín de Montiano, cuyo predicamento en el ámbito de la tragedia neoclásica era innegable, no era una práctica infrecuente entre las escritoras ${ }^{22}$. En este caso, sin embargo, la aparente humildad con la que la autora confiesa haberse sometido al ilustrado juicio y a las oportunas sugerencias de Montiano $^{23}$ enmascara

${ }^{21}$ En opinión de Hickey, toda obra ha de enseñar y estimular, como corresponde a una concepción ilustrada del teatro, «el heroísmo, el buen modo de pensar y de proceder honrosamente, el pundonor, el respeto [...] que consiste en la observancia y práctica de las virtudes morales o cristianas: la fidelidad al esposo, a los padres, al soberano, a la religión, a la patria, etc.» (XIII)

${ }_{22}$ Véanse, a modo de ejemplo, las tres aprobaciones y las licencias de impresión con las que María Catalina de Caso «blinda» su traducción del Modo de enseñar y estudiar las bellas letras de Rollin (1755).

23 «Concluida mi traducción la remití a D. Agustín de Montiano y Luyando [...] para que su mucha instrucción, buen gusto e inteligencia en estas materias, se sirviese darme su parecer, y corregir y enmendar en la obra todo lo que su buen juicio hallase necesitar de enmienda y corrección» (III). 
una reivindicación por vía indirecta su propio talento: por eso, además de incluir al final del prólogo la elogiosa carta que le envió el director de la Real Academia de la Historia valorando positivamente su traducción de Andromaque, Hickey no pierde la oportunidad de recalcar que el manuscrito devuelto por Montiano contenía apenas unas «leves y reducidas» notas del erudito que en nada tocaban a la sustancia de la obra, eximiéndola incluso, dice, «después de hacerme mucho favor y aplaudir mi tarea» (IV), de la obligación de eliminar la consonancia en el verso, que ella había mantenido del original francés por no apartarse «escrupulosamente del sentido de los conceptos, pensamientos y expresiones del original» (IV).

Es así como, desde sus primeras líneas, Margarita Hickey ofrece a sus lectores la clave del «pacto» a partir del cual habrán de adentrarse en las siguientes páginas (prólogo autorial y traducción de Racine), que ostentan la singularidad de ser producto de una pluma femenina: la cualificación de su autora, ratificada por una autoridad competente en la materia, para bregar airosamente con uno de los padres de la tragedia francesa y, de paso, para emitir juicios en materia de poética dramática.

De hecho, amparada por las alabanzas de Montiano, la autora aprovecha el prólogo no solo para reivindicar su arte de «traducir bien», como dice el académico en su carta, resaltando la aplicación y el acierto de la escritora ${ }^{24}$, sino también para hacer exhibición de una doble inquietud teórica: sobre la opción traductora elegida por ella para verter a Racine al español y, al hilo de lo anterior, sobre algunas de las cuestiones que eran objeto de debate en la poética de la tragedia neoclásica a lo largo de la segunda mitad del siglo.

Hickey dedica así sus primeras páginas a explicar y justificar una opción traductora propia, autónoma de consejos ajenos y respetuosa con el «sentido del Poeta» (V), con la «hermosura del original» (VI) y con los méritos de su autor, «tan justamente alabado y celebrado» (VI): «... me he determinado por fin a dar al público la Andrómaca del celebrado Racine, traducida al castellano tan fielmente que ni en pasaje ni en expresión alguna he querido alterarla: sin embargo de que algunos me aconsejaban lo contrario cuando la traducía» (VI).

Esta ferviente declaración de fidelidad al original ${ }^{25}$ se apoya en la renuencia de la autora a querer «enmendar, corregir y mudar» (VI) una muestra dramá-

${ }^{24}$ «He leído con especial gusto la traducción de la Andrómaca que Vm. se sirve mandarme reconocer, y restituyo con algunas leves enmiendas, que nada tocan a la sustancia de la obra. [...] Repito, Señora, que estas correcciones no son sustanciales, y que sin ellas merece no corto elogio su aplicación de Vm., y el acierto con que desempeña la suma dificultad de traducir bien» (Hickey 1789, XV).

${ }^{25}$ Desde la versión más literal hasta el tratamiento libérrimo del original, la literatura dieciochesca permite ejemplificar profusamente los diferentes grados de intervención del traductor en su obra, como bien ha mostrado Urzainqui (1991). García Garrosa y Lafarga señalan como predominante en el teatro la tendencia a «connaturalizar los originales en un 
tica cuyo valor principal es precisamente su carácter ejemplar en ese proceso de adaptación de la tragedia neoclásica que ella suscribe y estimula doblemente, a través de su práctica traductora y del aparato paratextual con que la envuelve. El hecho de traer la Andrómaca al territorio nacional, ofreciendo y adaptando un modelo de prestigio, campo en el que ninguna otra mujer española se ejercita hasta las postrimerías del XVIII, le permite no solo equipararse indirectamente con los insignes artífices de versiones de tragedias francesas a mitad de siglo (los académicos Juan de Trigueros o Eugenio Llaguno, por ejemplo), sino también aprovechar el «marco» que solía acompañar este tipo de obras para introducirse en el ámbito de la poética dramática y seguir la estela marcada por algunos de los próceres del arte trágico nacional como Luzán o Montiano, pretensión aún más insólita en una fémina por muy ilustrada que esta fuese.

La adaptación de la versificación gala a la asonancia hispánica es, por ejemplo, uno de los puntos que aborda Hickey en consonancia con las directrices establecidas por Montiano en sus dos discursos sobre las tragedias españolas -donde el académico rechaza el consonantismo propio del arte dramático francés por alejar el ritmo de la poesía dramática del discurso cotidiano, es decir, por no parecerse a la realidad ${ }^{26}$ - y defendidas por casi todos los preceptistas hasta finales de siglo ${ }^{27}$. Al calificar en su prólogo el consonantismo francés de tacha que peca «contra las reglas del arte» (IV), la autora hace gala de su conocimiento del discurso teórico sobre la tragedia, y, de paso, justifica el atrevimiento de haberse visto compelida a alejarse de Racine en algunas expresiones del original. En este sentido, la complejidad de conciliar el rigor traductor con el deseo de nacionalización de la tragedia, aspecto muy señalado en los discursos que preceden a las versiones españolas de obras dramáticas, se hace evidente en el texto de Hickey a través de los aprietos -e incluso contradicciones- en los que se ve la autora para explicar la evolución desde aque-

proceso traductor que implicaba identificarse con el autor original y adaptar luego su obra a la realidad social, cultural y literaria española» $(2009,36)$, opción que no es, desde luego, la elegida por Hickey.

26 Tanto en el primero como en el segundo de los Discursos, Montiano se declara partidario del verso suelto para evitar la monotonía resultante del endurecimiento del metro propio de la rima consonante $(1750,111,113 ; 1753,110)$. En general, tanto el romance heroico como las combinaciones libres de asonantes, de consonantes y de versos sueltos fueron del gusto de los preceptistas de la tragedia.

${ }^{27}$ Estala, por ejemplo, señala lo siguiente: «¿Pero quién podrá sufrir aquel continuo martilleo de los pareados alexandrinos, que invariablemente han de marchar de dos en dos cual yunta de bueyes, sino los oídos más que batavos, que ya han hecho callo a tan insufrible monotonía? Nuestro romance, ya el endecasílabo para la tragedia, ya el octosílabo para la comedia, tiene una armonía siempre varia y muy grata al oído, no ofende con el artificio manifiesto de la rima, no obliga a violentar y estropear los conceptos, y admite todas las gracias y sublimidad de la poesía más artificiosa» $(1793,47)$. 
lla su primera versión de Andrómaca redactada a mitad de siglo, fiel al consonantismo francés, a esta segunda en la que, según reconoce, la voluntad de librarse de aquel «defecto» propio del teatro del país vecino la obligó a extender algo más los pensamientos y conceptos (IV), aunque sin alejarse -se justifica- «poco ni mucho del sentido del Poeta» (V).

En este prurito de fidelidad respetuosa con el sentido, que garantiza la preservación de la sustancia del original, estriba la diferencia fundamental, según señala ella misma, entre su traducción y la versión de la Andrómaca más difundida en la escena española, la de Pedro de Silva, publicada en 1764 con el seudónimo de Joseph Cumplido y bajo título de El Astianacte, y profusamente representada hasta $1801^{28}$. Las libertades que se toma Silva con la obra de Racine, «alterada y desfigurada en lo más principal y esencial de este género de composiciones» (VII), obligan a Hickey a matizar bien el título de su propia versión (Andrómaca. Ningún amor aventaja en nobles y heroicas almas al amor de gloria y fama) para diferenciarla de aquella otra Andrómaca «defectuosa»-dice- y conocida como Al amor de madre no hay afecto que le iguale. Por otro lado, los desmanes melodramáticos de Silva sirven a la autora para reivindicar sus propios méritos así como para introducir en su argumentación dos cuestiones inexcusables en toda poética dramática de inspiración neoclásica: el carácter heroico de los personajes trágicos, es decir, su necesaria ejemplaridad socio-moral y la concepción del teatro como escuela pública de buenas costumbres.

Frente a la utilidad social fácilmente extraíble de la historia de Andrómaca propuesta por Racine (promover simultáneamente la virtud individual y la defensa de los intereses colectivos), los cambios introducidos por Silva en el

${ }^{28}$ Las versiones de Hickey y de Silva se encuentran tan alejadas como lo están sus fuentes. La autora sigue fielmente la historia tal como la dramatiza Racine; Silva, por el contrario, adapta la versión libre de Apostolo Zeno, realizada - a partir de la del dramaturgo francés y de varias otras fuentes (Eurípides, Séneca)- para la ópera Andromaca, que se estrenó en Viena (1724). Así lo reconoce él mismo en la «Advertencia al que leyere» que abre su edición de la obra con el título El Astianacte (1764). En esta "Tragedia nueva», como la subtitula Silva, más cercana al teatro heroico-sentimental que a la tragedia clásica, es el propio Orestes, convertido en antihéroe, quien hiere a Pirro, mientras que Andrómaca, creyéndolo muerto, se enamora de él repentinamente fascinada por la virtud del monarca, la cual, por otro lado, no se había apreciado hasta el momento en la obra. El giro melodramático lo aporta Pílades, quien rapta a Astianacte, hijo de Andrómaca. En la escena final, Hermione, dispuesta a cualquier cosa por amor, devuelve al niño para salvar la vida de Orestes. Pirro, héroe de esta sorprendente versión, pone fin a este singular enredo amoroso-familiar liberando a Orestes por devoción a Andrómaca.

La Andrómaca de Silva, que, a la vista está, satisfacía sobradamente la afición al sentimentalismo y al enredo de los espectadores de finales del XVIII, fue representada en numerosas ocasiones entre 1764 y 1801 con títulos diversos, tal como se explica en la nota 15: Al amor de madre no hay afecto que le iguale, El astianacte, La Andrómaca (Andioc y Coulon 1996, II: 614 y 884). 
diseño de los personajes rebajan considerablemente, en opinión de Hickey, la necesaria ejemplaridad trágica de héroe y heroína. Absolutamente soliviantada se muestra la autora, por ejemplo, ante la volubilidad amorosa de la Andrómaca de Silva, más humana que la de Racine en su disposición a amar a un Pirro convertido en salvador de su hijo Astianacte, pero también menos heroica y, por tanto, de menor capacidad purgativa ${ }^{29}$; tampoco ahorra Hickey invectivas contra la bajeza moral de un Orestes con la «execrable osadía» de atentar contra la vida de su rey a instancias de Hermione y de hacerlo, además, en escena sin disimulo ninguno ${ }^{30}$ :

29 «la tal Andrómaca del autor español (que es la heroína principal de la pieza) merece bien poco, o nada ese nombre, pues empezando su representación manifestando un odio implacable contra su vencedor Pirro, luego a pocos lances e instancias de este, pasa repentinamente de un extremo a otro, y del odio y rencor va debilísimamente al del amor, y se rinde y entrega vergonzosamente al destructor de su casa, de su reino y de su esposo; cosa muy opuesta al verdadero heroísmo, y al que Racine hace observar y guardar a su heroína en esta misma tragedia, pues la hace preferir y anteponer el morir y quitarse ella misma la vida valerosamente, al hecho feo e impropio de dar la mano y casarse con el matador de su esposo, y destructor de su reino y familia» (Hickey: VII-VIII). En la obra de Silva, de hecho, se potencia el contraste entre la virtud del rey y la bajeza moral de Orestes, un recurso habitual en la tragedia del período para el diseño de los personajes, como estudia Narciso García-Plata (2002, 327-343).

${ }_{30}$ Ya nos explicó Sala Valldaura cómo a partir de 1766 el magnicidio -ni tan siquiera como refuerzo de las tesis absolutistas- y los episodios cruentos dejaron de ser puestos en escena, intensificándose la concepción de la tragedia como una lección de «patriotismo regalista y filoaristocrático» (121). La reticencia a recurrir al tiranicidio como solución dramática se mantiene hasta final de siglo, como vemos en Numa (1799) de González del Castillo o en Zorayda de Álvarez de Cienfuegos (1798). Por otro lado, como bien señala Checa Beltrán (1998, 205-206), el debate sobre si convenía representar o no las muertes en escena acompañó a la tragedia española desde bien temprano. Aunque Luzán en su Poética reconocía el efecto catártico de las muertes en el teatro («hará más efecto y moverá más la vista de un caso atroz»), también recomendaba -siguiendo a Paolo Beni- que las más bárbaras e inhumanas se relataran indirectamente a través del diálogo de los personajes (1977, 492-494). En la misma línea, Montiano, en su Discurso sobre las tragedias españolas, rechaza las muertes excesivas en escena y se conforma también con el relato de las mismas «para el movimiento de las pasiones» $(1750,38)$. La idea se mantiene a lo largo de la segunda mitad del XVIII, como vemos aún en 1791 en Las reglas del drama de Quintana $(1821,201)$ y en la pluma de Santos Díez González: «Pero en cualquiera clase de tragedia se debe huir de presentar a vista de los espectadores en el teatro escenas atroces y sanguinarias que los horroricen» $(1793,105)$.

Resaltemos que, a pesar de las agrias críticas de Hickey a su rival, en la melodramática versión de Pedro de Silva, Pirro no solo no sucumbe al ataque de Orestes, sino que se convierte en salvador del niño Astianacte. Con esta vuelta de tuerca, Silva sortea el escollo del «tiranicidio», quedando la figura real reivindicada y engrandecida además por su amor a Andrómaca. Esta «humanización» del rey era, como bien ha mostrado Cañas Murillo, recurso habitual de la comedia de espectáculo dieciochesca, en cuya puesta en práctica coincide en gran medida con la tragedia neoclásica, distanciándose ambas de la visión teocéntrica de la monarquía propia de la comedia barroca $(2017,410-414)$. 
Y asimismo Orestes, en el autor francés se representa un héroe que [...] no se atreve a poner la mano en Pirro para matarle como su amada lo exigía de él, [...] y se reduce o limita solamente a consentir que los griegos lo ejecuten: [...] pero aun este hecho atroz no pasa en el teatro, sino que solo se relata y refiere, por no poner a la vista de los espectadores un hecho tan infame y de tan mal ejemplo [...], mas en el autor español, no solo se ejecuta en el teatro esta acción sacrílega y abominable, sino que el mismo Orestes es el que a vista de todos tiene la execrable osadía de dar con su propia mano de puñaladas a Pirro en el templo a traición y alevosamente, como pudiera hacer el pillo más despreciable (VIII-IX).

En la tragedia traducida por Hickey es precisamente «la saña animosa» de «la plebe alborotada» la responsable de la muerte del tirano Pirro, aunque dicha acción ocurre fuera de escena y se insiste en que el rey moribundo se defiende «con valerosa constancia» de la «cruel saña» de los griegos (Hickey 1789, 125-126). Pese a todo, especialmente difícil era justificar, ya avanzado el año de 1789 -fecha de publicación del volumen de Hickey y también de la intensificación de la revuelta francesa contra el absolutismo monárquico- el que el pueblo griego acabara con la vida de su rey, incluso siendo este un déspota insensible. Por eso, aunque en su «Prólogo» Hickey incluye -eso sí, de pasadala imprescindible reprobación autorial contra esta «acción sacrílega y abominable», «hecho atroz», «infame y de tan mal ejemplo», prefiere desviar la atención del lector hacia las debilidades de la versión de Silva, como los deslices en la virtud femenina o en la honorabilidad del héroe trágico, indecoroso espejo en el que pudiera contemplarse «un público respetable, civilizado y bien instruido» (IX).

Con esta encendida repulsa a la versión de Silva, la autora en realidad está asumiendo una posición teórica ante un conocido conflicto entre dos formas de entender las vías por las que había de circular el drama nacional: la concepción más estricta -más neoclásica, más reformista-, que hacía prevalecer la utilidad pública de la tragedia sobre su condición de divertimento, y otra vía más flexible, que pretendía compatibilizar, aun a costa de ciertas concesiones de fondo, los modelos dramáticos prestigiosos con los procedimientos y los recursos al alza en el gusto popular (los efectos melodramáticos, lo lastimoso, la peripecia, algunos resortes de lo heroico, etc.). A tenor del éxito teatral que acapararon las traducciones/adaptaciones de algunas obras de Du Belloy, Lemierre, Crébillon, Sauvigny, etc., así como las versiones menos ortodoxas de algunos de los clásicos franceses como Racine y Corneille (Qualia 1943), es evidente que los defensores de la adecuación de la tragedia a la complacencia de los espectadores españoles no predicaban en el desierto.

En esta línea argumentativa se inscribía también un jovencísimo Pedro de Silva - que sería a la larga director de la RAE- en la «Advertencia al que leyere» de su citada edición de El Astianacte (1764). Allí, escudándose tras el seudónimo de «Joseph Cumplido», el autor explicaba que esta su opera prima ya había sido estrenada en el teatro, la reconocía como una versión libre -«en 
cuanto a la sentencia»-de la Andromaca operística e italiana de Apostolo Zeno $\mathrm{y}$, para justificar su alejamiento de la tradición raciniana, apuntaba hacia el «dar gusto» como regla principal del arte dramático, señalando que la pretensión de su adaptación era lograr la conciliación de «nuestro teatro»-es decir, el compuesto en obsequio del vulgo- y el buen gusto neoclásico:

Y como el ejemplo es de suyo más eficaz, y más claramente demuestra, que cualquier disertación, me resolví a tentar vado tan peligroso, formando una pieza, que unos, y otros adoptasen sin dificultad; los vulgares, por hallarla en muchas cosas parecida a las demás de esta especie, que ellos tanto aprecian, los entendidos por no hallar en ella las más de las circunstancias, que les hacen aquellas despreciables. [...] Por fin, yo me daré por muy bien pagado, y satisfecho de mi trabajo, si consigo desvanecer en parte aquella ya comunísima aprehensión, que es imposible tener igualmente entretenidos, y atentos a la representación de una tragedia el vulgo y los eruditos (Silva 1764, s.p.).

Aunque la intención final de Hickey, llevar la obra a las tablas conciliando lo útil y lo delectable, no dista tanto de la confesada por Silva, ambos difieren claramente en los límites -el grado de «desviación» de los principios neoclásicos- que contemplan para la connaturalización de la tragedia extranjera. Por eso, frente a la convicción con la que Silva reconoce haber seguido -y no precisamente con fidelidad- la libre y melodramática versión del asunto realizada por Zeno, Margarita Hickey no duda en arremeter contra aquellos traductores, como el propio Silva, responsables de la disolución del carácter heroico de los personajes trágicos, convertidos en modelos de debilidad o indignidad moral a cambio del mayor rédito en la espectacularidad de la obra.

Por eso insiste tanto la autora en señalar, insertándose en la línea argumentativa de los preceptistas de su tiempo ${ }^{31}$, que

el Teatro es una escuela pública a la que una gran parte de gente va a aprender, a pensar y a proceder, y que por esta razón no se deben presentar en ella al pueblo sino acciones y documentos que puedan enseñarle a pensar bien, y a bien proceder; singularmente en aquellas composiciones dramáticas en que el amor hace el primer papel (X).

${ }^{31}$ Apuntar al teatro como escuela pública era, de hecho, un lugar común en los textos y paratextos de los dramaturgos interesados en introducir un nuevo gusto teatral en suelo patrio. Así se observa desde mitad de siglo, cuando Montiano señalaba en su Discurso II sobre las tragedias españolas que el teatro debía ser una escuela para moderar instructivamente las costumbres (3), a los años más intensos del «reformismo» neoclásico (véase, por ejemplo, el «Prólogo del autor» al Ensayo sobre el teatro español de Tomás Sebastián y Latre en 1772) para alcanzar hasta la última década de la centuria, en la que Mariano Luis Urquijo defendía el mismo asunto a lo largo del prólogo a su traducción de La mort de César: «La mudanza del teatro, eregido [sic] en pública escuela de política, de elocuencia, de buen gusto, y de recto modo de pensar, ciertamente ocasionó grandes ventajas al humano ingenio» (30). 
Y apuntando directamente hacia quienes deben velar por que tales propiedades del teatro se respeten escrupulosamente, añade Hickey

que es verdaderamente digno de admiración y de extrañarse que no se cele sobre este particular más de lo que en él se cela para que no se dejasen representar tales monstruosidades por las pésimas consecuencias que de sus representaciones pueden seguirse (IX).

Las recomendaciones de la autora en este punto, en doble sintonía con la ideología ilustrada y con la ideología de género asumida, pasan por tratar los asuntos amorosos con decencia y decoro, sin confundir la pasión, dice, con el «vago deseo, con el vicioso apetito, y con el abandono y el libertinaje» (X). Precisamente la comedia nueva Las vivanderas ilustres de Valladares de Sotomayor, estrenada en la capital poco más de un año antes de la publicación de las Poesías varias (García Garrosa 1993, 679), es citada por Hickey -que insiste en no haberla leído ni visto representar- como paradigma de la disolución moral y del pernicioso ejemplo ${ }^{32}$ que tales obras constituyen para «tanta joven inocente que las ve representar» (XI).

Además de la falta de habilidad de los autores dramáticos para tratar con el decoro necesario la pasión, también desaprueba la escritora en extensa nota al pie los amores «empalagosos, insípidos y fastidiosos, en los que amantes y amados se derriten mutuamente de amor sin ningún fruto ni provecho» (XII) ${ }^{33}$. Queda clara la posición autorial respecto a la presencia de la temática amorosa en las composiciones dramáticas, donde solo caben los amores dirigidos «a algún fin heroico y de buen exemplo; sin cuya circunstancia», sentencia Hickey «no se debe admitir esta pasión [...] según mi dictamen (y según el de otros más autorizados que el mío), como lo expreso y hago ver en otro discurso que sobre este particular va puesto al final del $2^{\circ}$ tomo de esta obrita» (XII).

Lamentablemente, este segundo discurso de la autora aleccionando a sus lectores sobre la propiedad moral que debían guardar las representaciones teatrales nunca vio la luz, como tampoco lo hizo el volumen II de sus Poesías varias. Aun así, el «Prólogo» a este primer tomo nos deja ver cómo, a un paso

32 Recordemos que en Las vivanderas ilustres Rosalía es engañada por el Marqués de la Colina, y que de esta seducción nace una niña «ilegítima», por lo que la protagonista se ve obligada a fugarse de su patria y a vender víveres para mantenerse. Es evidente que este «parto furtivo o fortuito» (XI), como lo denomina Hickey, no satisface los estándares de decoro y moralidad que el teatro, en opinión de la autora, debe mantener. «Dejo a la consideración y al juicio de los cuerdos y prudentes», concluye, «el decidir si se debe permitir la representación de casos tan obscenos, indecentes y vergonzosos» (XI).

${ }_{33}$ Así se quejaba de esto mismo Quintana en Las reglas del drama (1791) tan solo dos años más tarde: «otro camino/ La moderna Melpómene escogiendo,/ Más que a aterrar, a enternecer se avino/ Y despojada del severo atuendo/ Que en la escena ateniense la seguía,/ De solo amor se la escuchó gimiendo./ Más dulce voz, más plácida armonía/ Adquirió así tal vez; más degradarse/ Se vio el coturno con vergüenza un día» $(1821,198)$. 
ya de la última década de siglo, ante la invasión de comedias sentimentales, la tergiversación del espíritu de lo trágico a manos de los autores de teatro mayoritario (José Concha, Zavala y Zamora, Comella, etc.) y la cada vez mayor permeabilidad de la tragedia a los resortes de la sensibilidad (véase, por ejemplo, el Numa de González del Castillo, la Zorayda de Cienfuegos o las obras de María Rosa de Gálvez, Alí-Bek, Blanca de Rossi, La delirante, El egoísta...), Hickey se mantiene firme en la defensa de los grandes valores del género (mover a la virtud, al heroísmo, al bien común, etc.) y en una pedagogía de lo amoroso destinada tanto a reforzar la ideología socio-familiar vigente como a desviar la atención de cualquier otra lectura menos «ortodoxa» de la obra que traducía. Es evidente $-\mathrm{y}$ a buen seguro no casual en tiempos de movimientos populares y de acometidas al absolutismo monárquico- que la autora soslaya en su prólogo cualquier referencia a la potencial lectura política de la Andromaque de Racine (donde la plebe iracunda somete y asesina al tirano), y en su lugar carga las tintas sobre el valor pedagógico/ejemplar del heroísmo maternal de Andrómaca (madre de Astianacte en lo privado y «madre» del pueblo troyano en lo público) para la juventud ilustrada ${ }^{34}$.

Un guiño final a las autoridades eclesiásticas, especialmente vigilantes con los escasos frutos de la pluma femenina, cierra el prólogo de Margarita Hickey, quien recomienda que en toda pieza teatral -como en la traducida por ella- se estimule «el buen modo de pensar y de proceder» (XIII) que comprende la observancia de las virtudes morales y cristianas así como la fidelidad a la autoridad familiar, religiosa y política. Como rúbrica a su prólogo, la definición que ofrece Hickey de lo que ha de ser una composición dramática secunda las

${ }^{34}$ Así lo deja claro la autora en el «Prólogo» cuando elogia calurosamente el heroísmo de la Andrómaca raciniana, que antepone «el morir y quitarse ella misma la vida valerosamente, al hecho feo e impropio de dar la mano y casarse con el matador de su esposo, y destructor de su reino y familia» (VIII).

Comparando la traducción de Hickey con la de Silva, Catherine Flepp observa cierta contención en el prólogo de la autora a la hora de insistir en la faceta maternal de Andrómaca, que interpreta como un rechazo a ver en ella un modelo de virtud maternal inspirado por una reivindicación feminista $(2010,492)$. Sin cuestionar, desde luego, la profunda conciencia de género que demuestra Hickey tanto en la selección de la materia literaria para sus traducciones como en su propia obra de creación poética, el hecho de resaltar el carácter heroico de Andrómaca tratando de refilón el asunto del «amor maternal» -el cual, por otro lado, era incuestionable en la obra de Racine-, responde, en mi opinión, a una reivindicación de naturaleza más dramática que feminista, que convendría relacionar también con la escasa simpatía generada en la autora por la repentina pasión amorosa de la heroína hacia Pirro en la traducción de Silva: se trataba, en suma, de distanciarse de los efectos o recursos claramente «melodramáticos», más propios de la denostada comedia de teatro que de la tragedia neoclásica; por eso en su prólogo Hickey muestra a Andrómaca como paradigma de una heroicidad que, sin dejar de ser femenina, es tan colectiva como personal, y por eso sus sentimientos íntimos -su amor de madre hacia Astianacte o su posible inclinación hacia Pirro- aparecen soslayados o sencillamente obviados en el discurso paratextual de la autora. 
líneas del reformismo ilustrado, incluyendo tanto la concepción del teatro como entretenimiento imprescindible para la sociedad de su tiempo como la necesidad de que este se ejercite en la dificultosa empresa del docere delectans:

Una composición dramática no es otra cosa que un poema moral, y como tal debe ser bueno y doctrinal para que sea provechoso; que este es el único medio de que este género de diversión, tan precisa e indispensable en las grandes poblaciones, pueda ser, y sea efectivamente a un mismo tiempo útil y delectable: dos puntos estos, procurados conciliar por muchos, y logrado de pocos (XIII).

En su conjunto, la digresión preliminar de Hickey se nos revela como un valioso e inusual ejercicio de autoridad femenina en materia de reflexión teórica sobre la tragedia en las últimas décadas del siglo. Desviándose de las líneas que conforman la práctica habitual en la labor paratextual de las escritoras de su tiempo, la voz de Margarita Hickey no reclama en ningún momento una distinción de género, ni para obtener un tratamiento literario diferenciado ni para excusar o justificar una impericia femenina en la que no se reconoce y a la que no recurre ni tan siquiera como tópico al uso. Muy al contrario, escudada en el prestigio de Racine y en la autoridad «nacional» de Agustín de Montiano, no solo se postula como traductora de tragedia «clásica» y se ejercita en la crítica dramática, sino que opina sin ningún género de titubeo sobre los derroteros por los que ha de circular la escena nacional, atreviéndose a marcar directrices de política teatral e incluso a reconvenir sutilmente a las instituciones encargadas de velar por ella.

Todo ello, claro está, desde una práctica discursiva fiel al reformismo neoclásico y respetuosa con la ortodoxia pedagógica, religiosa y moral esperable de la mano femenina que rubrica el texto. Sin duda la labor de Margarita Hickey es singular en su conjunto: por la selección de la materia literaria a partir de la cual realiza su traducción, obra de un maestro indiscutible de la tragedia clásica francesa al que ninguna otra mujer trae a suelo nacional en el siglo XVIII; por las fechas -tempranas- en las que emprende su primera traducción de Andrómaca a mitad de siglo, cuando esta obra no ha llegado todavía a la escena española y cuando ninguna otra autora española se asoma siquiera aún al género trágico; por la inusual confianza que demuestra en sus propias dotes literarias y por su perseverancia en hacer pública su obra, empeño que se extiende a lo largo de dos décadas; y sobre todo, por el envoltorio teórico que arropa su versión de Racine, donde nos ofrece el primer ejercicio femenino de «poética» dramática al servicio del buen gusto neoclásico.

\section{BIBLIOGRAFÍA CITADA}

Andioc, René y Mireille Coulon. 1996. Cartelera teatral madrileña del siglo XVIII (17081808). 2 vols. Toulouse: Presses Universitaires du Mirail. 
Berbel, José Juan. 2003. Orígenes de la tragedia neoclásica española: la Academia del Buen Gusto (1737-1754). Sevilla: Universidad de Sevilla.

Burriel, Antonio. 1757. Compendio del Arte Poética, sacado de los autores más clásicos, para el uso e instrucción de los Cavalleros seminaristas del Real Seminario de Nobles de Madrid. Madrid.

Cañas Murillo, Jesús. 2010. «Teatro neoclásico para representaciones particulares: Polixena Tragedia en un acto fácil de executarse». Anuario de Estudios Filológicos XXXIII: 39-63.

Cañas Murillo, Jesús. 2013. «El poderoso como personaje y como tema en la tragedia neoclásica española». Cuadernos de Ilustración y Romanticismo 19: 85-109.

Cañas Murillo, Jesús. 2017. «Dos estéticas frente a un tema: Monarquía y monarcas entre la tragedia neoclásica española y el teatro popular de la Ilustración». En El dominio de la realidad y la crisis del discurso. El nacimiento de la conciencia europea, coord. Concepción Camarero Bullón y Juan Carlos Gómez Alonso, 395-421. Madrid: Polifemo.

Coca Ramírez, Fátima. 2000. «La influencia de la "comedia sentimental” en la poética del "drama histórico" y de la "tragedia neoclásica" a principios del siglo XIX en España». Cuadernos de Ilustración y Romanticismo 8: 115-130.

Checa Beltrán, José. 1996. «La teoría de la tragedia en Estala». En Teatro español del siglo XVIII, coord. José María Sala Valldaura, I, 243-264. Lleida: Universidad de Lleida.

Checa Beltrán, José. 1998. Razones del buen gusto. (Poética española del Neoclasicismo). Madrid: CSIC.

Checa Beltrán, José. 2003. «La teoría teatral neoclásica». En Historia del teatro español, dir. Joaquín Huerta Calvo, II, 1519-1552. Madrid: Gredos.

Checa Beltrán, José. 2015. «Nacionalismo literario y canon en el siglo XVIII: García de la Huerta y Bourgoing». En Vicente García de la Huerta y su obra (1734-1787), ed. Jesús Cañas Murillo, Miguel Ángel Lama y José Roso Díaz, 19-44. Madrid: Visor.

Cotarelo y Mori, Emilio. 1897. Iriarte y su época. Madrid: Sucesores de Rivadeneyra.

Deacon, Philip. 1988. «Vicente García de la Huerta y el círculo de Montiano: La amistad entre Huerta y Margarita Hickey. Revista de Estudios Extremeños XLIV, 2: 395-421.

Díez González, Santos. 1793. Instituciones poéticas. Madrid: Benito Cano.

Establier Pérez, Helena. 2017. «La materia inglesa en la tragedia neoclásica española de finales del XVIII: La Estuarda y el femenil ingenio de María Martínez Abello». Bulletin of Spanish Studies XCIV, 5: 771-793.

Estala, Pedro. 1793. «Discurso preliminar sobre la tragedia antigua y moderna». En Edipo tirano, 3-50. Madrid: Sancha.

Fernández Cabezón, Rosalía. 2012. «La tragedia neoclásica española». En El teatro en la España del siglo XVIII. Homenaje a José María Sala Valldaura, coord. Judith Farré-Vidal, Nathalie Bittoun-Debruyne y Roberto Fernández, 95-110. Lleida: Universidad.

Flepp, Catherine. 2010. «Traduire Andromaque au XVIIIe. siècle: perméabilité du genre». Collection des travaux du CREC 7: 482-512. http://crec-paris3.fr/wp-content/ uploads/2011/07/ancien-et-nouveau-16-Flepp.pdf Consultado el 17-11-2016.

Forestier, Georges. 1998. «Écrire Andromaque. Quelques hypothèses génétiques». Revue d'Histoire Littéraire de la France 1: 43-62.

Forsyth, Elliot. 1983. "The tensions of classicism in the French theatre of the seventeenth century». En The classical temper in Western Europe, ed. John Hardy y Adam McCredie, 47-61. Melbourne: Oxford University Press.

García Garrosa, M. Jesús. 1993. «La Real Cédula de 1783 y el teatro de la Ilustración». Bulletin Hispanique 95 (2): 673-692.

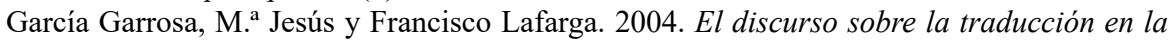
España del siglo XVIII: estudio y antología. Kassel: Reichenberger. 
García Garrosa, M. J Jesús y Francisco Lafarga. 2009. «La historia de la traducción en España en el siglo XVIII». En La traducción en la época ilustrada (panorámicas de la traducción en el siglo XVIII, ed. José Antonio Sabio Pinilla, 27-80. Granada: Comares.

García Malo, Ignacio. 1788. «Prólogo». En Doña María Pacheco, mujer de Padilla. Madrid: Viuda de Miguel Escribano.

García Menéndez, Javier. 2002. «La configuración de la tragedia neoclásica en España y Portugal». Theatralia 4: 245-273.

Guerra, Francisco. 1764. Asunto séptimo y décimo octavo de los propuestos, en que se prueba ser más útil la tragedia que la comedia para civilizar y ilustrar una Nación. Madrid: Francisco Javier García.

Herr, Richard. 1964. España y la revolución del siglo XVIII. Madrid: Aguilar.

Hickey, Margarita. 1789. Poesías varias. Sagradas, morales, y profanas ó amorosas: con dos poemas épicos en elogio del Capitán General D. Pedro Cevallos, el uno dispuesto en forma de diálogo entre la España y Neptuno: concluido este, y el otro no acabado por las razones que en su Prólogo se expresan; con tres Tragedias Francesas traducidas al Castellano: una de ellas la Andrómaca de Racine, y varias piezas en prosa de otros Autores, como son algunas Cartas Dedicatorias, y Discursos sobre el Drama, muy curiosos e instructivos. Obras todas de una dama de esta corte. Tomo Primero. Madrid: en la Imprenta Real.

Lafarga, Francisco. 1982. Voltaire en España. Oxford: The Voltaire Foundation.

Lafarga, Francisco. 1983-1988. Las traducciones españolas del teatro francés (1700-1835). 2 vols. Barcelona: Universidad de Barcelona.

Lafarga, Francisco. 1997. El teatro europeo en la España del siglo XVIII. Lleida: Universitat de Lleida.

Lafarga, Francisco (ed.) 1999. La traducción en España (1750-1830). Lengua, literatura, cultura. Lleida: Universitat de Lleida.

Lafarga, Francisco. 2004. «El siglo XVIII, de la Ilustración al Romanticismo». En Historia de la traducción en España, ed. Francisco Lafarga y Luis Pegenaute, 209-319. Salamanca: Ambos Mundos.

Lafarga, Francisco. 2013. «La traducción de piezas extranjeras como vía hacia la modernidad en el teatro español del siglo XVIII». MonTI 5: 299-324. https://doi.org/10.6035/ MonTI.2013.5.13

López de Sedano, Juan. 1763. «Préfacion». En Jahel. Tragedia sacada de la Sagrada Escritura. Madrid: Joachim Ibarra.

López Pinciano, Alonso. 2006. Epistolas sobre el arte dramático. De «Filosofía antigua poética». Madrid: UNAM.

Luzán, Ignacio de. 1977. La Poética o reglas de la poesía en general y de sus principales especies. Edición de Russell P. Sebold. Barcelona: Labor. Primera edición completa de ambos textos dieciochescos (1737 y 1789).

Martínez Cuadrado, Jerónimo. 1995. «Recepción de la dramaturgia raciniana en la España diceciochesca (ayer y hoy de Racine en España)». Anales de Filología Francesa 7: 91-110.

Montiano y Luyando, Agustín de. 1750. Discurso sobre las tragedias españolas. Madrid: Joseph de Orga.

Montiano y Luyando, Agustín de. 1753. Discurso II sobre las tragedias españolas. Madrid: Joseph de Orga.

Moreno González, Tadeo. 1788. «Motivo de la composición desta pieza». En El Axtianacte. Tragedia nuevamente escrita en tres actos. Biblioteca Nacional, MSS/15797.

Narciso García-Plata, Reyes. 2002. «Nueva aproximación al estudio del contraste en la tragedia neoclásica: los personajes». Anuario de Estudios Filológicos XXV: 327-343. 
Natan, Stéphane. 2013. «Andromaque de Racine, vraie fausse hérö̈ne tragique?». Neohelicon 40: 245-260.

Nieto Ibáñez, Jesús M. ${ }^{a}$ 2004. «Historia y mitos grecorromanos en la tragedia neoclásica española». Silva 3: 305-331.

Palacios Fernández, Emilio. 2002. La mujer y las letras en el siglo XVIII. Madrid: Ediciones del Laberinto.

Pierucci, Daniela. 2006. «Introduzione». En Margarita Hickey, Poesías, 13-69. Pisa: Edizioni ETS.

Postigo, Juan Francisco del. 1765. Combates de amor y ley. Cádiz: Manuel Espinosa de los Monteros.

Qualia, Charles B. 1939. «Racine's Tragic Art in Spain in the Eighteenth Century». PMLA 54 (4): 1059-1076.

Qualia, Charles B. 1943. «The Vogue of Decadent French Tragedies in Spain 1762-1800». PMLA 58 (1): 149-162.

Quintana, Manuel José. 1821. «Las reglas del drama. Ensayo didáctico. Notas». En Poesías, II, 185-228. Madrid: Imprenta Nacional.

Ríos Carratalá, Juan Antonio. 1984. «Nuevos datos sobre el proceso de García de la Huerta». Anales de Literatura Española 3: 413-427.

Ríos Carratalá, Juan Antonio. 1987. Vicente García de la Huerta: (1734-1787). Badajoz: Departamento de Publicaciones de la Excma. Diputación.

Ríos Carratalá, Juan Antonio. 1997. "“La tragedia francesa” y "Traducciones de tragedias francesas"». En El teatro europeo en la España del siglo XVIII, Francisco Lafarga, 6386 y 205-234. Lleida: Universitat de Lleida.

Rodríguez Sánchez de León, María José. 1999. La crítica dramática en España (1789-1833). Madrid: CSIC.

Rohou, Jean. 2000. «De Pertharite à Andromaque: les enseignements d'une comparaison historique». Papers on French Seventeenth Century Litetature 27 (52): 57-84.

Roso Díaz, José. 2009. «El tipo del héroe en la tragedia Pelayo de Manuel José Quintana». En Medievalismo en Extremadura. Estudios sobre Literatura y Cultura Hispánicas de la Edad Media, ed. Jesús Cañas Murillo, Francisco Javier Grande Quejigo y José Roso Díaz, 605-617. Cáceres: Universidad de Extremadura

Sala Valldaura, José María. 2005. «El horrible y sensible final de la verosimilitud o la tragedia neoclásica de finales del siglo XVIII». En Similitud y verosimilitud en el teatro del Siglo de Oro, coord. Isabel Ibáñez, 353-371. Pamplona: Ediciones Universidad de Navarra. Anejos de RILCE, 52.

Sala Valldaura, José María. 2006. De amor y política: la tragedia neoclásica española. Madrid: CSIC.

Salgado, María Antonia. 1992. «El autorretrato clandestino de Margarita Hickey, escritora ilustrada». En L'autoportrait en Espagne. Littérature et pinture, ed. Guy Mércadier, 133-147. Aix en Provence: Université de Provence

Salgado, María Antonia. 1994. «Reescribiendo el canon: Góngora y Margarita Hickey». Dieciocho 17 (1): 17-31.

Sánchez Barbero. 1805. Principios de Retórica y Poética. Madrid: Imprenta de la Administración del Real Arbitrio de Beneficencia.

Sebastián y Latre, Tomás. 1764. «Al público». En Británico. Tragedia de Mr. Juan Racine. Zaragoza: Imprenta de Francisco Moreno.

Sebastián y Latre, Tomás. 1772. «Prólogo del autor». En Ensayo sobre el teatro español (precediendo a dos comedias «arregladas» por el autor: Comedia de Progne y Filomena, de Rojas, y El parecido en la Corte de Moreto). Zaragoza: Imprenta del Rey. 
Silva y Sarmiento, Pedro de (Seud. Joseph Cumplido). 1764. «Advertencia al que leyere». En El astianacte. Tragedia nueva. Por otro título Al amor de madre no hay afecto que le iguale. Madrid: Gabriel Ramírez.

Sullivan, Constance. 1997. «A biographical note on Margarita Hickey». Dieciocho 20 (2): 219-236.

Tolívar Alas, Ana Cristina. 1984. Traducciones y adaptaciones españolas de Racine en el siglo XVIII. Tesis doctoral inédita. Universidad de Oviedo.

Tolívar Alas, Ana Cristina. 1991. «Phèdre de Racine en la España del siglo XVIII». En Traducción y adaptación cultural España-Francia, ed. M. ${ }^{\mathrm{a}}$ Luisa Donaire y Francisco Lafarga, 433-442. Oviedo: Servicio de Publicaciones de la Universidad.

Tolívar Alas, Ana Cristina. 1995. «El teatro de Racine en la España de los primeros Borbones». En Teatro y traducción, coord. Francisco Lafarga y Roberto Dengler, 59-70. Barcelona: Universitat Pompeu Fabra.

Tolívar Alas, Ana Cristina. 2001. «La réception de Racine dans l'Espagne du XVIIIe. Siècle». En Recepción de autores franceses de la época clásica en los siglos XVIII y XIX en España y en el extranjero, ed. Mercé Boixareu y Roland Resné, 127-137. Madrid: UNED

Urquijo, Mariano Luis. 1791. La muerte de César: Tragedia francesa de Mr. De Voltaire: Traducida en verso castellano y acompañada de un discurso del traductor sobre el estado actual de nuestros teatros y necesidad de su reforma. Madrid: Don Blas Román.

Urzainqui, Inmaculada. 1991. "Hacia una tipología de la traducción en el siglo XVIII: los horizontes del traductor». En Traducción y adaptación cultural: España-Francia, ed. M. ${ }^{a}$ Luisa Donaire y Francisco Lafarga, 623-638. Oviedo: Universidad de Oviedo.

Urzainqui, Inmaculada. 1997. «Poética teatral: presencia y prestigio de los críticos extranjeros». En El teatro europeo en la España del siglo XVIII, ed. Francisco Lafarga, 15-59. Lleida: Edicions Universitat de Lleida.

Zorrozua, Santiesteban, María del Pilar. 1999. Escritoras de la Ilustración española (17591808). Bilbao: Departamento de Publicaciones de la Universidad de Deusto.

Fecha de recepción: 24 de enero de 2017.

Fecha de aceptación: 28 de noviembre de 2017. 